OPEN ACCESS

Edited by:

Alan Jay Katz,

St. Francis Hospital, United States

Reviewed by:

Fabiana Gregucci,

Ospedale Generale Regionale

Francesco Miulli, Italy

Natasa Milickovic,

Sana Klinikum Offenbach, Germany

Stefanie Corradini,

LMU Munich University Hospital,

Germany

*Correspondence:

Efstratios Karagiannis

karagiannis.efstratios@gmail.com

Specialty section:

This article was submitted to

Radiation Oncology,

a section of the journal

Frontiers in Oncology

Received: 24 October 2021

Accepted: 31 January 2022

Published: 01 March 2022

Citation:

Karagiannis E, Strouthos I,

Leczynski A, Zamboglou N and Ferentinos K (2022) Narrative

Review of High-Dose-Rate

Interstitial Brachytherapy in

Primary or Secondary Liver Tumors.

Front. Oncol. 12:800920.

doi: 10.3389/fonc. 2022.800920

\section{Narrative Review of High-Dose-Rate Interstitial Brachytherapy in Primary or Secondary Liver Tumors}

\author{
Efstratios Karagiannis ${ }^{1,2 *}$, Iosif Strouthos ${ }^{1,2}$, Agnes Leczynski ${ }^{1}$, Nikolaos Zamboglou ${ }^{1,2}$ \\ and Konstantinos Ferentinos ${ }^{1,2}$ \\ ${ }^{1}$ Department of Radiation Oncology, German Oncology Center, Limassol, Cyprus, ${ }^{2}$ Department of Medicine, School of \\ Medicine, European University Cyprus, Nicosia, Cyprus
}

The optimal management of intrahepatic malignancies involves a multidisciplinary approach. Although surgical resection has been considered the only curative approach, the use of several minimally invasive ablative techniques has dramatically increased the last two decades, mainly due to the fact that they provide similar oncological results with significantly decreased morbidity. Among these modalities, interstitial liver brachytherapy, probably the most flexible liver ablative method, with excellent clinical data on its safety and effectiveness, is frequently not even mentioned as an option in the current peer reviewed literature and guidelines. Brachytherapy is a type of radiotherapy utilizing radionuclides that are directly inserted into the tumor. Compared to external beam radiation therapy, brachytherapy has the potential to deliver an ablative radiation dose over a short period of time, with the advantage of a rapid dose fall-off, that allows for sparing of adjacent healthy tissue. For numerous malignancies such as skin, gynecological, breast, prostate, head and neck, bladder, liver and soft-tissue tumors, brachytherapy as a monotherapy or combined with external beam radiation therapy, has become a standard treatment for many decades. This review article aims to describe the high-dose-rate liver brachytherapy technique, its selection criteria, present its advantages and disadvantages, as well as the available clinical data, in order to help physicians to explore and hopefully introduce liver brachytherapy into their clinical routine.

Keywords: liver cancer, liver metastases, HDR brachytherapy, liver brachytherapy, interstitial brachytherapy

\section{INTRODUCTION}

With primary liver cancer being the seventh most commonly diagnosed cancer worldwide (1), while liver is the most common site of metastasis in patients with colorectal cancer (2), primary and secondary liver malignant tumors are frequently encountered. The best approach to optimize the management of these intrahepatic malignancies seems to be one that utilizes a core multidisciplinary liver tumor board, consisting of gastroenterologists/hepatologists, diagnostic and interventional radiologists, pathologists, surgical oncologists, medical oncologists, as well as radiation oncologists (3). 
Although increasingly shifting, surgical approaches (transplantation or resection) remain the gold standard for patients with primary or secondary liver cancer. However, the majority of patients (80-90\%) are poor surgical candidates due to age and comorbid medical conditions, functional status, severity of hepatic decompensation, unfavorable anatomical lesions location, insufficient future liver remnant, extent of metastases, history of extensive abdominal surgery or patient's preferences (4-8). Against this background, over the last decades, several minimally invasive liver directed treatment modalities, including image-guided ablative and trans-arterial techniques (9), have been developed and are being used alone or in combination with traditional and newer systemic treatments, improving patient outcomes. As there is a whole armamentarium of such modalities (Table 1), it is crucial not only to choose the most appropriate but also the most suitable technique for each modality, tailoring the treatment concept to patient and tumor characteristics. Among these liver directed treatment modalities, interstitial brachytherapy (BT), probably the most flexible liver ablative method, with excellent available clinical data on its effectiveness and safety $(10,11)$, is frequently not even mentioned as an option in the current peer reviewed literature and guidelines. This article aims to describe the liver BT technique and its selection criteria, present its advantages and disadvantages, as well as the available clinical data in order to help the clinical decision-making process for patients needing a liver ablative treatment modality.

\section{BACKGROUND}

Although liver directed treatments have rapidly evolved the last decades, their efficacy or safety might be limited by tumor size,

TABLE 1 | Liver directed modalities for primary and secondary liver tumors.

\section{Transarterial Techniques}

Conventional trans-arterial chemoembolization (cTACE)

Chemotherapy bound to embolic particles in drug-eluting bead TACE (DEB-TACE)

Transarterial bland embolization (TAE)

Transarterial radioembolization (TARE)

Hepatic arterial infusion chemotherapy (HAl)

Ablation Techniques

Chemical Ablation

Percutaneous intralesional ethanol injection (PEI)

Percutaneous intralesional acetic acid injection (PAl)

Thermal Ablation

Radiofrequency ablation (RFA)

Microwave ablation (MWA)

Laser interstitial thermotherapy (LITT)

High intensity focused ultrasound (HIFU)

Cryosurgical ablation (CSA)

Other

Electrochemotherapy (ECT)

Irreversible electroporation (IRE)

Radiotherapy Ablation

Stereotactic Ablative Radiotherapy (SABR): photons, particles

Brachytherapy (BT): High-Dose-Rate, Low-Dose-Rate) location, number of lesions, and/or amount of functional liver remnant (12-15), serious complications rate $(14,16)$, technique reproducibility and inconsistency $(16,17)$, or patient characteristics, such as implanted cardiac devices (18), cardiac arrhythmias (19), prior treatments and pathological lung shunt fraction (LSF) (20). Liver interstitial BT, and more specifically high-dose-rate (HDR) liver BT, as an alternative to the other liver-directed modalities has none of the above limitations. It is not limited by tumor size and localization or liver/tumor-specific density, blood perfusion rate, specific heat, electrical or thermal conductivity. Additionally, taking into account that larger radiation dose leads to greater cellular kill probability, the major advantage of BT lies in the physical dose distribution surrounding the radioactive source (most commonly Ir-192). While very high, precisely predicted radiation doses, able to sterilize all tumor cells, are delivered intra-tumoral, the steep dose fall-off, outside the tumor-target, accounts for greatly reduced doses to the surrounding healthy tissues. All the above can lead to excellent local disease control with minimal toxicity.

\section{HISTORY OF LIVER BRACHYTHERAPY}

The concept of interstitial liver brachytherapy, as it is known today, was first described by Dritschilo et al. in 1986 (21). They have reported an ultrasound-guided, percutaneous placement of a 14 gauge closed-ended needle suitable for attachment to the Gamma Med II Ir-192 remote after-loader (Palo Alto, CA) in local anesthesia. The use of computed tomography (CT)-based treatment planning, as well as the prescribed dose of up to 50Gy to volumes up to $25 \mathrm{~cm}^{3}$ in a single fraction, became major reference points for the evolution of liver brachytherapy. One year later, the same group (Georgetown group) reported their experience with intraoperative single fraction interstitial liver BT (22), while the Memorial Sloan Kettering group published the first low-dose-rate (LDR) liver BT results in 1990 (23). Although liver BT in Europe began in the late 1990s, the first systematic reports were published in the 2000s. Zamboglou, a believer in BT and a longtime BT pioneer, was the first to perform liver BT in Europe and the first to introduce CT-guidance for catheter insertion worldwide (24). The Offenbach group has reported the results of 31 patients with inoperable primary and secondary liver tumors, treated between 2000 and 2009 with CT-guided interstitial BT (10), while the Magdeburg group introduced a novel catheter implantation technique, which uses a trochar puncture needle, that is exchanged over a stiff angiographic guide wire for a flexible 6-F catheter sheath using Seldinger's technique and the subsequent replacement of the wire by a closed-end 6F BT catheter, and reported their first results back in 2004 (25). It has to be noted that the extended clinical research conducted by Ricke et al. (Magdeburg Group), regarding multiple aspects of liver HDR BT, such as organs at risk (OARs) tolerance dose assessment (26-29), dose and fractionation evaluation $(11,30)$, magnetic resonance imaging (MRI) and positron emission tomography (PET) introduction in guidance and implantation accuracy, treatment planning, as well 
as tumor/tissue radiation response $(29,31-34)$ expanded the knowledge base of the whole brachytherapy community. The first experience regarding the feasibility of MRI-guided liver brachytherapy was published in 2001 by Kettenbach et al. (35).

\section{PATIENT SELECTION}

As aforementioned, in the dynamic area of hepatic oncology, the value of a liver specific multidisciplinary board cannot be overstated. It is widely accepted that every patient should undergo formal evaluation by such a multidisciplinary tumor board. In general, liver HDR-BT patient selection criteria are similar to other ablation techniques, with BT being much more flexible in terms of location, size, and number of lesions. Heat or cold sink effects, proximity to major bile ducts are less of an issue for BT, if at all, than for thermal ablation techniques. Similarly, inter- or intra-fractional liver (and other OARs) motion, lesion size and location, as well as future liver reserve are less of a concern for BT compared to Stereotactic Ablative Radiation (SABR) (36).

Due to the lack of an international consensus defining (in) eligibility criteria for liver BT candidates, every institution has developed its own approach. Our inclusion/exclusion criteria are presented in Table 2 .

\section{TECHNIQUE}

\section{Preplanning}

Radiation dose delivery in HDR-BT, using the common afterloading technique, involves the positioning of non-radioactive, closed-ended catheters in the tumor-target and the subsequent loading of them with the radiation source (usually Ir-192). The source travels through the catheters and remains in predetermined positions (dwell positions) for a predetermined time (dwell time), in order to deliver the prescribed dose. As the possible dwell positions are physically constrained by the catheter path, accurate catheter positioning is essential.
Currently, pre-implant three-dimensional (3D) imaging is commonly used to manually determine the number and the position of the catheters. Virtual needles are usually placed to provide "optimal" dwell positions for a desired dose distribution, while maintaining a safe catheter access route. Although for small spherical lesions the pre-planning procedure is straightforward, for larger liver tumors and moreover in the proximity of OARs, defining the optimal number of catheters, their spatial configuration and the ideal spatiotemporal source stepping pattern within them, in the era of anatomy-based 3D planning, can be technically challenging (37). Unfortunately, computerized techniques based on mathematical optimization models, which can effectively solve these problems and provide superior implant quality, are not widely implemented in liver BT (38-40).

In our institution a deep expiration or inspiration breath-hold CT fused with pre-acquired liver specific MRI data is used for the inverse pre-planning procedure, followed by delineation of planning tumor volume (PTV), OARs and avoidance regions, including major vessels, gallbladder, bile ducts or dilated biliary channels. Virtual catheters, proposed by the hybrid inverse planning and optimization (HIPO) algorithm (40) for complex implants or manually determined for simpler implants, are placed, so that all selected dosimetric (PTV, OARs) and anatomical objectives (safe catheters pathway) are met. The dosimetric constraints used in published studies, as well as in our institution are described in Table 3. It has to be noted that in the majority of liver brachytherapy clinical studies more conservative dose constraints were used. We recommend using the tighter and more extensively studied constraints into clinical practice (Table 3). For cases where the dose to the stomach, duodenum, jejunum, ileum or colon is a limiting factor, balloon catheters can be used (48).

\section{Catheter Placement}

Interstitial catheter implantation is usually performed under sedoanalgesia and local anesthesia enabling image guidance (US, CT, MRI). Breath hold techniques similar to pre-planning procedure are commonly used. Two similar catheter placement approaches have been described, with one incorporating the Seldinger technique (25) and one without this interventional

TABLE 2 | German Oncology Center (GOC) inclusion/exclusion criteria for HDR liver BT.

Inclusion Criteria

Hepatobiliary Cancer

Hepatocellular Carcinoma

Intrahepatic

Cholangiocarcinoma

Oligometastatic liver disease
Non-metastatic, unresectable tumor, transplant candidate (as bridge therapy) Non-metastatic, unresectable tumor(s), not transplant candidate (as definitive therapy), $\leq 4$ liver lesions Non-metastatic tumor(s), non-surgical candidate (as definitive therapy), $\leq 4$ liver lesions Oligometastatic disease ( $\leq 3$ extrahepatic lesions amenable to locoregional treatment), $\leq 4$ liver lesions in combination with systemic Tx. Recurrent/oligorecurrent/oligoprogressive intrahepatic disease (individualized concept)

Non-metastatic, unresectable tumor(s), $\leq 4$ liver lesions, in combination with systemic Tx Non-metastatic tumor(s), non-surgical candidate, $\leq 4$ liver lesions, in combination with systemic $T x$ Oligometastatic disease ( $\leq 5$ metastatic lesions amenable to locoregional treatment), $\leq 4$ liver lesions in combination with systemic Tx. Recurrent/oligoreccurent intrahepatic disease (individualized concept)

$\leq 4$ liver lesions, with controlled extrahepatic disease or $\leq 3$ extrahepatic lesions amenable to locoregional Tx in combination with systemic Tx

Recurrent/oligorecurrent/oligoprogressive intrahepatic disease (individualized concept) 
TABLE 3 | German Oncology Center (GOC) dosimetric constraints for HDR liver BT.

\begin{tabular}{|c|c|c|c|}
\hline Target/OARs & $\begin{array}{l}\text { Constraints used in clinical } \\
\text { studies }\end{array}$ & GOC Constraints & GOC Special considerations \\
\hline PTV (Target) & $\mathrm{D} 100 \%=\mathrm{PD}(11,25,30,41)$ & V100\% > 95\% & PD: $25 \mathrm{~Gy}$ \\
\hline Healthy liver tissue (Liver-GTVs) & $\begin{array}{l}\text { V5Gy }<2 / 3 \text { liver volume }(11,25 \\
30,41,42) \\
\text { V10Gy }<2 / 3 \text { liver volume }(43)\end{array}$ & $\begin{array}{l}\text { V10Gy }<2 / 3 \text { liver volume and } \\
\text { 700cc }\end{array}$ & $\begin{array}{l}\text { For Re-irradiation*: V40Gy }\left(\Sigma \mathrm{EQD}_{3 \mathrm{~Gy}} 2\right)<2 / 3 \text { liver volume } \\
\text { and } 700 \mathrm{cc}\end{array}$ \\
\hline $\begin{array}{l}\text { Esophagus/Stomach/Duodenum/ } \\
\text { Jejunum/lleum }\end{array}$ & $\begin{array}{l}\text { D1cc }<15 \text { Gy }(11,27,30,44,45) \\
\text { D1cc }<12 \text { Gy }(46) \\
\text { Dmax }<15 \text { Gy }(47) \\
\text { Dmax }<14 \text { Gy }(42)\end{array}$ & D1cc $<15 G y$ & For Re-irradiation*: D1cc < 85Gy( $\Sigma$ EQD $\left._{3 G y} 2\right)$ \\
\hline Colon & $\begin{array}{l}\text { D1cc }<15 \text { Gy }(11,30) \\
\text { Dmax }<18 G y(42)\end{array}$ & $\mathrm{D} 1 \mathrm{cc}<15 \mathrm{~Gy}$ & \\
\hline Spinal Cord & $\begin{array}{l}\text { D1cc < 8Gy }(11,30) \\
\text { Dmax }<15 G y(47)\end{array}$ & D1cc $<14 G y$ & For Re-irradiation*: D1cc < 75Gy( $\left.\Sigma \mathrm{EQD}_{3 \mathrm{~Gy}} 2\right)$ \\
\hline $\begin{array}{l}\text { Kidneys (for GOC: individual and } \\
\text { combined) }\end{array}$ & V7Gy < 2/3 kidney volume (43) & $\begin{array}{c}\text { D1cc < 18Gy } \\
\text { D200cc < 10Gy } \\
\text { Dmean }<6 \text { Gy }\end{array}$ & $\begin{array}{l}\text { For Re-irradiation*: D1cc }<90 G y\left(\Sigma E E_{3 G y} 2\right) \\
\text { D200cc }<40 G y\left(\Sigma E D_{3 G y} 2\right) \\
\text { Dmean }<16 G y\left(\Sigma E D_{3 G y} 2\right)\end{array}$ \\
\hline Thoracic Wall & No constraint & D1cc < 23Gy & For Re-irradiation*: D1cc < 110Gy $\left(\Sigma E_{3 G} D_{3 G}\right)$ \\
\hline Great Vessels & No constraint & D1cc $<27 G y$ & For Re-irradiation*: D1cc < 240Gy( $\left.2 E^{\star} Q D_{3 G y} 2\right)$ \\
\hline Gallbladder & Dmax < 20Gy (42) & No constraint & Mandatory reporting of D1cc and Dmean \\
\hline
\end{tabular}

radiology procedure step $(10,21)$. Regardless of implantation technique, the implant geometry should ideally replicate the virtual plan's geometry, in order to achieve the user-selected dose distribution objectives. Upon completion of catheter placement, post-implant non-enhanced or contrast-enhanced CT/MRI images of the liver are acquired for the $3 \mathrm{D}$ treatment planning. Photo-documentation of the implant, catheter numbering and free-length (length of needles outside the patient) measurement, directly after the image acquisition, as well as patient transport to the treatment room, avoiding catheter displacement, is of great importance.

\section{Treatment Planning}

CT-based planning is the treatment planning technique of choice, especially when TG-186 dose calculation algorithms are used (49). If TG-43 formalism and its updates are used (50-52), MRI-based planning is also feasible. Following the catheters reconstruction (digitization) and volumes of interest (VOIs) delineation, which include PTVs and OARS, a 3D-anatomy-based plan can be generated. In our institution a combined $3 \mathrm{~mm}$ isotropic expansion of the gross tumor volumes (GTVs) to PTVs is used. Catheters reconstruction and VOIs delineation are simultaneously performed, which significantly reduces the treatment planning procedure time. The typical prescribed dose covering the $95 \%$ of the PTVs is $25 \mathrm{~Gy}$ in a single fraction (Table 3). After the plan evaluation and the catheters free-length verification, the treatment can be delivered. Proton-pump inhibitors, serotonin 5-HT3 receptor antagonists and low-dose corticosteroids are administered routinely before treatment delivery.

\section{Clinical Results}

With almost 20 years of clinical experience with HDR-BT of liver tumors, there is a large amount of published data. Most of them are chronologically presented in Table 4 . Ricke et al. were the first to prospectively analyze the brachytherapy outcome of 36 secondary and two primary liver tumors ranging from 2.5 to
$11 \mathrm{~cm}$ (mean $4.8 \mathrm{~cm}$ ) in 37 patients (25). Twenty-one patients were treated with CT-guided HDR-BT alone, while sixteen patients received brachytherapy directly after MRI-guided laserinduced thermotherapy (LITT) due to suspected incomplete thermal ablation, mainly because of tumor size or location. They reported local control rates of $87 \%$ for the HDR-BT-group and $73 \%$ for the LITT followed by HDR-BT-group at 9 months and an OS rate of $69 \%$ at 12 months for all patients combined. One year later, Ricke et al. published the results of a prospective nonrandomized phase II trial, which included 20 patients with an equal number of large (up to $10 \mathrm{~cm}$ ) or unfavorably located for thermal ablation, primary and secondary liver tumors (41). LC was $80 \%$ and $53 \%$ at 6 and 9 months respectively, while OS was $83 \%$ at 12 months. The same group explored the local tumor control in colorectal liver metastases after HDR-BT at various dose levels and managed to demonstrate a strong dependency between tumor control and dose escalation (29). The LC was 75\% at 15 months for the whole cohort of patients and 95\% if doses $>25$ Gy were prescribed. Mohnike et al. treated 83 patients presented with 140 hepatocellular carcinomas (HCC), generating a LC rate of $95 \%$ and an OS rate of $64 \%$ at 12 months (30). The study by Schnapauff et al. investigated the clinical outcome of 15 patients with unresectable intrahepatic cholangiocarcinoma, treated with HDR-BT (53). After a median follow-up of 18 months, the median LC was 10 months and the median OS was 14 months after HDR-BT and 21 months after the initial diagnosis. Wieners et al. reported on 115 hepatic metastases of breast cancer in 41 patients (44). They were treated in 69 interventions using the most commonly used single fraction approach. LC was $97 \%, 93.5 \%$ and $93.5 \%$, while OS was $97 \%$, $79 \%$ and $60 \%$ at 6,12 and 18 months respectively. Collettini et al. shared their experience treating 7 patients with 12 isolated ovarian cancer metastases to the liver, generating a LC and OS rate of $100 \%$ at 12 months (59). The same group evaluated the clinical outcome of 35 patients with 19 large $(5-7 \mathrm{~cm})$ and 16 very large $(>7 \mathrm{~cm}) \mathrm{HCC}$, as well as the outcome of 8 patients with 12 solitary 
TABLE 4 | Clinical data regarding HDR-BT of primary and secondary liver tumors.

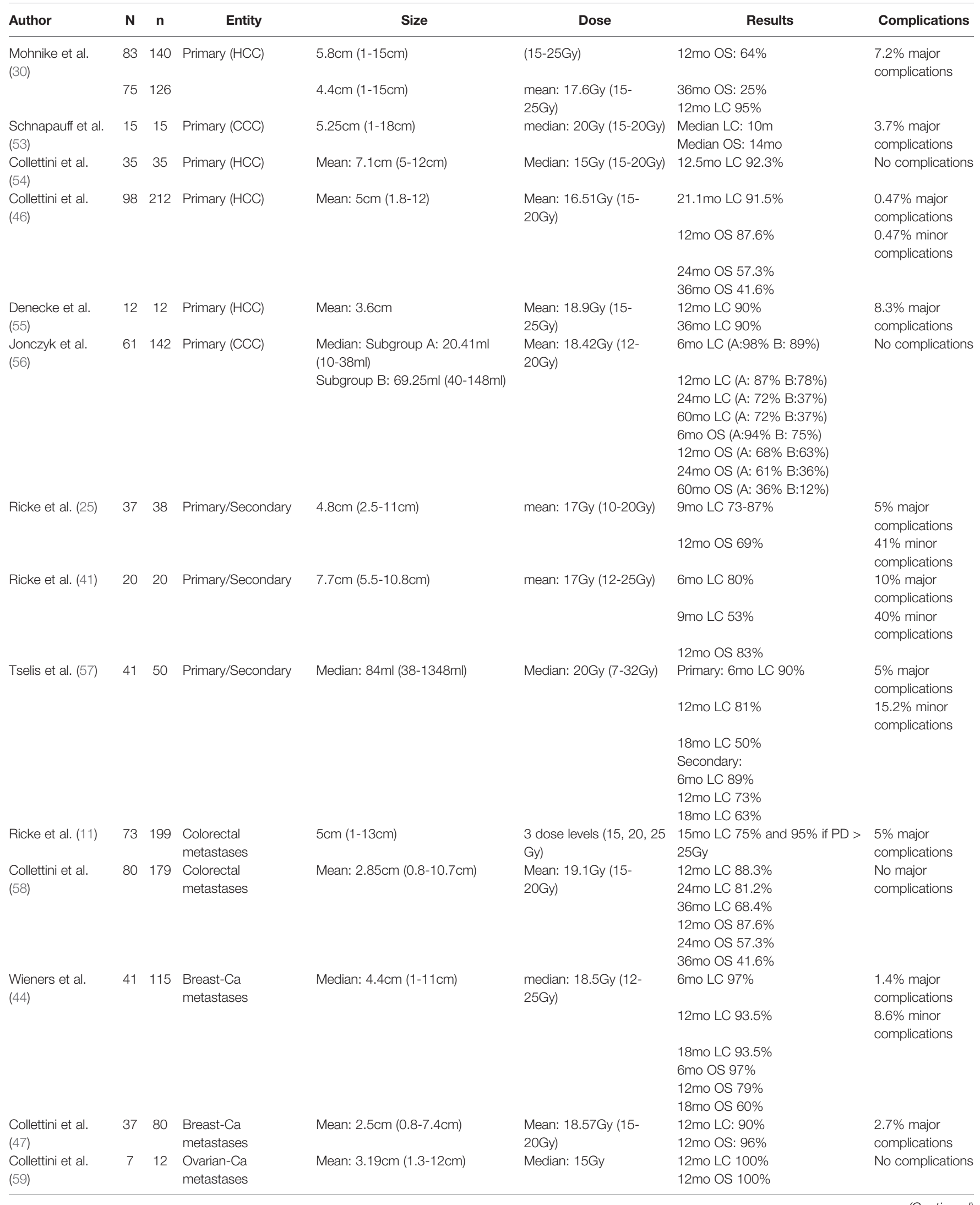


TABLE 4 | Continued

\begin{tabular}{|c|c|c|c|c|c|c|c|}
\hline Author & $\mathbf{N}$ & $\mathbf{n}$ & Entity & Size & Dose & Results & Complications \\
\hline Geisel et al. (60) & 8 & 12 & GEAC metastases & Median: 4.6cm (1.4-6.8cm) & Median: 20Gy (15-20Gy) & 8.4mo LC 100\% & $\begin{array}{l}11.1 \% \text { minor } \\
\text { complications }\end{array}$ \\
\hline $\begin{array}{l}\text { Schippers et al. } \\
\text { (43) }\end{array}$ & 27 & 52 & NELM & Mean: $3.1 \mathrm{~cm}(0.7 \mathrm{~cm}-11 \mathrm{~cm})$ & $\begin{array}{l}\text { Median: 20Gy (15-20 } \\
\text { +Gy) }\end{array}$ & $\begin{array}{l}12 \mathrm{mo} \text { LC } 92 \% \\
36 \mathrm{mo} \text { LC } 83 \% \\
60 \mathrm{mo} \text { LC } 83 \% \\
12 \mathrm{mo} \text { OS } 96 \% \\
36 \mathrm{mo} \text { OS } 96 \% \\
60 \mathrm{mo} \text { OS } 63 \%\end{array}$ & $\begin{array}{l}2.5 \% \text { minor } \\
\text { complications }\end{array}$ \\
\hline Geisel et al. (61) & 10 & 16 & RCC metastases & Median: $3.8 \mathrm{~cm}(1-8.2 \mathrm{~cm})$ & Median: 20Gy & $\begin{array}{l}\text { 12mo LC: } 90 \% \\
12 \text { mo OS: } 100 \%\end{array}$ & $\begin{array}{l}\text { No major } \\
\text { complications }\end{array}$ \\
\hline Omari et al. (62) & 14 & 54 & RCC metastases & Mean: $2.9 \mathrm{~cm}(0.7-13.9 \mathrm{~cm})$ & $\begin{array}{l}\text { Median: 16.1Gy (6.5- } \\
\text { 27.4Gy) }\end{array}$ & $\begin{array}{l}\text { 10mo LC: } 92.6 \% \\
\text { Median OS: } 51.2 \mathrm{mo}\end{array}$ & $\begin{array}{l}\text { No major } \\
\text { complications } \\
16.2 \% \text { minor } \\
\text { complications }\end{array}$ \\
\hline $\begin{array}{l}\text { Wieners et al. } \\
(42)\end{array}$ & 20 & 49 & $\begin{array}{l}\text { Pancreas-Ca } \\
\text { metastases }\end{array}$ & Mean: $2.9 \mathrm{~cm}(1-7.3 \mathrm{~cm})$ & $\begin{array}{l}\text { Mean: 18.1Gy (15- } \\
\text { 20Gy) }\end{array}$ & $\begin{array}{l}\text { 12mo LC: } 91 \% \\
12 \mathrm{mo} \text { OS: } 45 \%\end{array}$ & $\begin{array}{l}15 \% \text { major } \\
\text { complications }\end{array}$ \\
\hline Drewes et al. (63) & 16 & 45 & $\begin{array}{l}\text { Pancreas- } \\
\text { Cametastases }\end{array}$ & Median: $2.2 \mathrm{~cm}(1-11.2 \mathrm{~cm})$ & $\begin{array}{l}\text { Median: 21Gy (5- } \\
\text { 29.1Gy) }\end{array}$ & $\begin{array}{l}\text { Median PFS: } 3.4 \mathrm{mo} \\
\text { Median OS: } 8.9 \mathrm{mo}\end{array}$ & $\begin{array}{l}\text { 18\% major } \\
\text { complications }\end{array}$ \\
\hline Kieszko et al. (45) & 61 & 73 & Secondary & Median: 42.9ml (2.7-174.9ml) & $\begin{array}{l}\text { Mean D9o:20.2Gy (15- } \\
\text { 25Gy) }\end{array}$ & $\begin{array}{l}\text { 6mo LC } 88.7 \% \\
12 \mathrm{mo} \text { LC } 70.7 \% \\
6 \mathrm{mo} \text { OS } 96.7 \% \\
12 \mathrm{mo} \text { os } 79.6 \%\end{array}$ & $\begin{array}{l}\text { No major } \\
\text { complications } \\
5 \% \text { minor } \\
\text { complications }\end{array}$ \\
\hline Kieszko et al. (45) & 61 & 73 & Secondary & Median: 42.9ml (2.7-174.9ml) & $\begin{array}{l}\text { Mean Dgo:20.2Gy (15- } \\
\text { 25Gy) }\end{array}$ & $\begin{array}{l}\text { 6mo LC } 88.7 \% \\
12 \mathrm{mo} \mathrm{LC} 70.7 \% \\
6 \mathrm{mo} \text { OS } 96.7 \% \\
12 \mathrm{mo} \text { OS } 79.6 \%\end{array}$ & $\begin{array}{l}\text { No major } \\
\text { complications } \\
5 \% \text { minor } \\
\text { complications }\end{array}$ \\
\hline
\end{tabular}

N, number of patients; $n$, number of lesions; HCC, hepatocellular carcinoma; CCC, cholangiocarcinoma; RCC, renal cell carcinoma; GEAC, gastro-esophageal adenocarcinoma; NELM, neuroendocrine liver metastases; LC, local control; OS, overall survival.

gastro-esophageal adenocarcinoma metastases (54, 60). After a median follow-up of 8 and 12 months, the LC rate was $100 \%$ and $92.3 \%$, for the patients with gastro-esophageal adenocarcinoma metastases and HCC respectively. Tselis et al. treated 41 patients with 50 unresectable primary and secondary liver tumors, reporting LC rates of $90 \%, 81 \%$ and $50 \%$ for primary and $89 \%$, $73 \%$ and $63 \%$ for metastatic tumors at 6, 12 and 18 months respectively (57). The study by Collettini et al. analyzed the results of 80 patients with 179 unresectable colorectal liver metastases treated with liver BT in a single or multiple fractions. LC rates were $88.3 \%, 81.2 \%$ and $68.4 \%$ while OS rates were $87.6 \%, 57.3 \%$, and $41.6 \%$ at 12,24 and 36 months respectively (58). The same authors reported on 98 patients with 212 unresectable HCCs using a single fraction technique, generating LC rates of $91.5 \%$ at 21.1 months, as well as OS rates of $87.6 \%, 57.3 \%$ and $41.6 \%$ at 12,24 and 36 months respectively (46). Denecke et al. explored the role of liver BT as bridging therapy for patients with HCC listed for liver transplantation, comparing it to trans-arterial chemoembolization (55). Their data show comparable or even better response and post-LT recurrence rates in favor of liver BT. Schippers et al. treated 27 patients with 52 neuroendocrine liver metastases in 40 sessions, reporting LC rates of $92 \%, 83 \%$ and $83 \%$, as well as OS rates of $96 \%, 96 \%$ and $63 \%$ at 12,36 and 60 months respectively (43). The study by Kieszko et al. evaluated the clinical outcome of 61 patients with 73 liver secondary tumors treated with HDR-BT. LC and OS rates were $88.7 \%, 70.7 \%$ and
$96.7 \%, 79.6 \%$ at 6 and 12 months respectively (45). Omari et al. investigated the results of 14 patients with 54 renal cell liver metastases, treated with liver BT, reporting LC rate of $92.6 \%$ at 10.1 months and median OS of 51.2 months (62).

All the included published studies (Table 3) conclude that liver brachytherapy is a safe treatment approach, suggesting average major and minor complication rates below $4 \%$ and $6 \%$ respectively. Mohnike et al. conducted the largest known study, regarding liver brachytherapy complications and risk factors. They evaluated 192 patients and 343 interventions and reported major complication rate of $4.1 \%$, equivalent to that reported for thermal ablation $(64,65)$. Major complications included hemorrhage grade III-IV (1.46\%), ascites grade II $(0.29 \%)$, ulcers $(0.87 \%)$, radiation induced liver disease $(0.5 \%)$, liver abscess (1.17\%) and bile duct obstruction (0.29\%), while minor complications included hemorrhage grade I (3.21\%), ascites grade I $(0.71 \%)$, pleural effusion grade I-II $(12.2 \%)$ and pneumothorax grade I-II (1.75\%). Pain and nausea were the most frequent patient reported symptoms (64).

\section{DISCUSSION}

Minimally invasive, image-guided ablation techniques are increasingly used for the treatment of primary or secondary liver malignancies, not only for patients that are poor or 
borderline surgical candidates but also for patients that prefer a minimally invasive procedure, with similar results. It should be noted, that although there are studies favoring surgery over ablation and vice versa $(66,67)$, these findings should be interpreted with caution, as currently, there are no results from randomized controlled trials (RCTs) available, directly comparing the outcome of an ablation method vs surgery. The eagerly awaited results of registered RCTs, such as the COLLISION (NCT03088150), the HELARC (NCT02886104) and the LAVA (ISRCTN52040363) trials, will hopefully enlighten this topic. Similarly, RCTs comparing available ablation methods, including liver HDR-BT, are needed.

Liver HDR-BT extends the therapeutic possibilities for hepatic lesions considering the limitations of more commonly used ablation techniques, as it is not limited by tumor size, location, number of lesions, and/or amount of functional liver remnant (12-15), serious complications rate $(14,16)$, technique reproducibility and inconsistency $(16,17)$ or patient characteristics such as implanted cardiac devices (18), cardiac arrhythmias (19), prior treatments and pathological lung shunt fraction (LSF) (20). The large amount of available clinical data suggests that liver HDR-BT is not only feasible and safe but also at least iso-effective or even superior to other ablation methods, considering that it generates similar oncologic outcomes, while most patients treated with liver HDR-BT were not appropriate candidates for other ablation techniques.

In the past, liver HDR-BT was almost exclusively offered as a palliative treatment with the aim of symptoms control and/or cytoreduction that could possibly delay the onset of further systemic therapies. Nowadays, with a better understanding of concepts such as oligometastasis or oligoprogression, liver HDRBT can be used as a potentially curative option, alone or in combination with traditional or newer systemic therapies, including immunotherapy. Emerging data suggest that the highly heterogeneous and conformal dose distribution of brachytherapy, may be optimal for enhancing the immunogenic capacity of radiation at a tumor site while minimizing off-target antagonistic effects on peripheral immune cells, serving as a method of in situ tumor vaccination.

Despite the promising clinical results, the minimal (if any) limitations, the cost-effectiveness and the immunogenic potential of liver BT, it is frequently not even mentioned as an option in the current peer reviewed literature and guidelines. The European Society of Medical Oncology (ESMO) was the first and till now (to the best of the authors' knowledge) the only society that includes liver HDR-BT as a treatment option in its clinical treatment guidelines for HCC and metastatic colorectal cancer. It is proven that all ablative techniques, when performed by experienced operators, can successfully treat primary or secondary liver tumors. At present, there is no ideal ablative technique that outperforms the rest. There are ablation techniques that may share technical aspects and are usually comparable, but each of them has unique advantages that make it the "optimal" technique in particular settings. In conclusion, the choice of the appropriate treatment method and technique should be multidisciplinary, based on patients' and tumors' characteristics, as well as the medical expertise provided by the given treatment center.

\section{FUTURE DIRECTIONS}

Although liver-BT has dramatically advanced in the last two decades, its main challenge remains the level of expertise required for implementing it into clinical practice. A brief look at the published data shows that unfortunately only a few centers offer this valuable treatment modality as an option. The reason is definitely not the lack of evidence demonstrating patients' benefit, but mostly the deficient education and training of the next generation of radiation oncologists, the real or perceived barrier of user dependency of BT, the lack of randomized trials including liver-BT, as well as reimbursement issues.

Regarding the education challenges, the brachytherapy and radiation oncology societies have to take action and carefully replan the radiation oncology residency programs, so that every resident has the opportunity to be exposed to the whole BT spectrum.

Eliminating the "user dependency" in BT is a more challenging step. With regard to liver-BT, widely accepted clinical practice guidelines for catheters-placement, tumor delineation, dose prescription, tolerance dose constraints and surveillance imaging modalities are absolutely required in order to minimize variations in treatment delivery and evaluation, making liver-BT more consistent and efficient. Additionally, the build of a worldwide accessible Common Liver BT Database, allowing to record anonymized clinical data would contribute to this direction. Closing the gap between what clinicians do and what scientific evidence supports, could be the solid base of multi-institutional randomized clinical trials allowing comparisons of liver-BT with other liver directed modalities. Finally, the clinical implementation of existing technologies such as electromagnetic tracking for catheter reconstruction, automatic applicator/templates digitization, 3d printing for custom applicators/templates design, or newer technologies, such as deep-learning methods for auto-segmentation, as well biological and radiobiological novelties such as diagnostic, predictive and prognostic biomarkers, is highly required.

Reimbursement is probably the most difficult issue to tackle. It is known that BT requires equipment, complex imaging, trained personnel and a lot of physician effort and reimburses so poorly, that centers offering it frequently incur a net financial loss. Healthcare providers have to understand that if clinical practices are unprofitable, they will fold, with major consequences for the patients but also for them in the long run.

\section{CONCLUSION}

Image-guided liver HDR-BT is a well-studied, safe and effective treatment with minimal toxicity. Although not endorsed by the majority of oncological societies, it is probably the most flexible liver ablation technique, as it is not limited by patient or tumor characteristics, being a valuable adjunct in the large toolbox of 
interventional and irradiation techniques, for the treatment of primary and secondary liver cancers.

\section{AUTHOR CONTRIBUTIONS}

All authors have made substantial contributions to all of the following:

\section{REFERENCES}

1. Bray F, Ferlay J, Soerjomataram I, Siegel RL, Torre LA, Jemal A. Global Cancer Statistics 2018: GLOBOCAN Estimates of Incidence and Mortality Worldwide for 36 Cancers in 185 Countries. CA: A Cancer J Clin (2018) 68:394-424. doi: 10.3322/caac. 21492

2. Sheth KR, Clary BM. Management of Hepatic Metastases From Colorectal Cancer. Clin Colon Rectal Surg (2005) 18(3):215-23. doi: 10.1055/s-2005916282

3. Siddique O, Yoo ER, Perumpail RB, Perumpail BJ, Liu A, Cholankeril G, et al. The Importance of a Multidisciplinary Approach to Hepatocellular Carcinoma. J Multidiscip Healthc (2017) 10:95-100. doi: 10.2147/ JMDH.S128629

4. Gervais DA, Goldberg SN, Brown DB. Society of Interventional Radiology Position Statement on Percutaneous Radiofrequency Ablation for the Treatment of Liver Tumors. J Vasc Interv Radiol (2009) 207 suppl:S342-7. doi: 10.1016/j.jvir.2009.04.029

5. Borie F, Bouvier A-M, Herrero A, Faivre J, Launoy G, Delafosse P, et al. Treatment and Prognosis of Hepatocellular Carcinoma: A Population Based Study in France. J Surg Oncol (2008) 98(7):505-9. doi: 10.1002/jso.21159

6. Gillams A, Goldberg N, Ahmed M. Thermal Ablation of Colorectal Liver Metastases: A Position Paper by an International Panel of Ablation Experts, The Interventional Oncology Sans Frontieres Meeting 2013. Eur Radiol (2015) 25:3438-54. doi: 10.1007/s00330-015-3779-z

7. Van Tilborg AA, Scheffer HJ, de Jong MC. MWA Versus RFA for Perivascular and Peribiliary CRLM: A Retrospective Patient- and Lesion-Based Analysis of Two Historical Cohorts. Cardiovasc Intervent Radiol (2016) 39:1438-46. doi: 10.1007/s00270-016-1413-3

8. Sotirchos VS, Petrovic LM, Gonen M. Colorectal Cancer Liver Metastases: Biopsy of the Ablation Zone and Margins can be Used to Predict Oncologic Outcome. Radiology (2016) 280:949-59. doi: 10.1148/radiol.2016151005

9. Padma S, Martinie JB, Iannitti DA. Liver Tumor Ablation: Percutaneous and Open Approaches. J Surg Oncol (2009) 100:619-34. doi: 10.1002/jso.21364

10. Tselis N, Chatzikonstantinou G, Kolotas C, Milickovic N, Baltas D, Chung TL, et al. Hypofractionated Accelerated Computed Tomography-Guided Interstitial High-Dose-Rate Brachytherapy for Liver Malignancies. Brachytherapy (2012) 11:507-14. doi: 10.1016/j.brachy.2012.02.006

11. Ricke J, Mohnike K, Pech M, Seidensticker M, Rühl R, Wieners G, et al. Local Response and Impact on Survival After Local Ablation of Liver Metastases From Colorectal Carcinoma by Computed Tomography-Guided High-DoseRate Brachytherapy. Int J Radiat Oncol Biol Phys (2010) 78:479-85. doi: 10.1016/j.ijrobp.2009.09.026

12. Seror O. Percutaneous Hepatic Ablation: What Needs to be Known in 2014. Diagn Interv Imaging (2014) 95:665-75. doi: 10.1016/j.diii.2014.04.002

13. Tombesi P, Vece FD, Sartori S. Radiofrequency, Microwave, and Laser Ablation of Liver Tumors: Time to Move Toward a Tailored Ablation Technique? Hepatoma Res (2015) 1:52-7. doi: 10.4103/2394-5079.155697

14. Ryan MJ, Willatt J, Majdalany BS, Kielar AZ, Chong S, Ruma JA, et al. Ablation Techniques for Primary and Metastatic Liver Tumors. World J Hepatol (2016) 8(3):191-9. doi: 10.4254/wjh.v8.i3.191

15. Illing R, Kennedy JE, Wu F, ter Haar GR, Protheroe AS, Friend PJ, et al. The Safety and Feasibility of Extracorporeal High-Intensity Focused Ultrasound (HIFU) for the Treatment of Liver and Kidney Tumours in a Western Population. Br J Cancer (2005) 93:890-5. doi: 10.1038/sj.bjc.6602803

16. Lencioni R, Petruzzi P, Crocetti L. Chemoembolization of Hepatocellular Carcinoma. Semin Intervent Radiol (2013) 30(1):3-11. doi: 10.1055/s-00331333648
- the conception and design of the manuscript

- administrative support

- provision of study materials

- collection and assembly of the data

- data analysis and interpretation

- manuscript writing

- final approval of manuscript

17. Kim C. Understanding the Nuances of Microwave Ablation for More Accurate Post-Treatment Assessment. Future Oncol (2018) 14(17):1755-64. doi: $10.2217 /$ fon-2017-0736

18. Skonieczki BD, Wells C, Wasser EJ, Dupuy DE. Radiofrequency and Microwave Tumor Ablation in Patients With Implanted Cardiac Devices: Is It Safe? Eur J Radiol (2011) 79:343-6. doi: 10.1016/j.ejrad.2010.04.004

19. Dollinger M, Beyer LP, Haimerl M, Niessen C, Jung EM, Zeman F, et al. Adverse Effects of Irreversible Electroporation of Malignant Liver Tumors Under CT Fluoroscopic Guidance: A Single-Center Experience. Diagn Interv Radiol (2015) 21(6):471-5. doi: 10.5152/dir.2015.14442

20. Mahnken AH. Current Status of Transarterial Radioembolization. World J Radiol (2016) 8(5):449-59. doi: 10.4329/wjr.v8.i5.449

21. Dritschilo A, Grant EG, Harter KW, Holt RW, Rustgi SN, Rodgers JE. Interstitial Radiation Therapy for Hepatic Metastases: Sonographic Guidance for Applicator Placement. AJR Am J Roentgenol (1986) 147 (2):275-8. doi: 10.2214/ajr.147.2.275

22. Nauta RJ, Heres EK, Thomas DS, Harter KW, Rodgers JE, Holt RW, et al. Intraoperative Single-Dose Radiotherapy. Observations on Staging and Interstitial Treatment of Unresectable Liver Metastases. Arch Surg (1987) 122(12):1392-5. doi: 10.1001/archsurg.1987.01400240038006

23. Donath D, Nori D, Turnbull A, Kaufman N, Fortner JG. Brachytherapy in the Treatment of Solitary Colorectal Metastases to the Liver. J Surg Oncol (1990) 44(1):55-61. doi: 10.1002/jso.2930440113

24. Zamboglou N. Interstitial Brachytherapy Possibilities, in New Developments in Interstitial Remote Controlled Brachytherapy. In: Zamboglou N, editor. New York: Zuckschwerdt (1997). p. 174-80.

25. Ricke J, Wust P, Stohlmann A, Beck A, Cho CH, Pech M, et al. CT-Guided Interstitial Brachytherapy of Liver Malignancies Alone or in Combination With Thermal Ablation: Phase I-II Results of a Novel Technique. Int J Radiat Oncol Biol Phys (2004) 58(5):1496-505. doi: 10.1016/j.ijrobp.2003.09.024

26. Ricke J, Seidensticker M, Lüdemann L, Pech M, Wieners G, Hengst S, et al. In Vivo Assessment of the Tolerance Dose of Small Liver Volumes After SingleFraction HDR Irradiation. Int J Radiat Oncol Biol Phys (2005) 62(3):776-84. doi: 10.1016/j.ijrobp.2004.11.022

27. Streitparth F, Pech M, Böhmig M, Ruehl R, Peters N, Wieners G, et al. In Vivo Assessment of the Gastric Mucosal Tolerance Dose After Single Fraction, Small Volume Irradiation of Liver Malignancies by Computed TomographyGuided, High-Dose-Rate Brachytherapy. Int J Radiat Oncol Biol Phys (2006) 65(5):1479-86. doi: 10.1016/j.ijrobp.2006.02.052

28. Pech M, Ricke J, Seidensticker M, Staskiewicz G, Wieners G, Mohnike K, et al. Assessment of the Tolerance Dose of the Hepatic Reticulo-Endothelial System (RES) After Single Fraction HDR-Irradiation: An in-Vivo Study Employing SSPIO. Strahlenther Onkol (2008) 184(6):302-6. doi: 10.1007/s00066-0081815-5

29. Seidensticker M, Seidensticker R, Mohnike K, Wybranski C, Kalinski T, Luess $\mathrm{S}$, et al. Quantitative In Vivo Assessment of Radiation Injury of the Liver Using Gd-EOB-DTPA Enhanced MRI: Tolerance Dose of Small Liver Volumes. Radiat Oncol (2011) 17(6):40. doi: 10.1186/1748-717X-6-40

30. Mohnike K, Wieners G, Schwartz F, Seidensticker M, Pech M, Ruehl R, et al. Computed Tomography-Guided High-Dose-Rate Brachytherapy in Hepatocellular Carcinoma: Safety, Efficacy, and Effect on Survival. Int Radiat Oncol Biol Phys (2010) 78(1):172-9. doi: 10.1016/j.ijrobp.2009.07.1700

31. Steffen IG, Wust P, Rühl R, Grieser C, Schnapauff D, Lüdemann L, et al. Value of Combined PET/CT for Radiation Planning in CT-Guided Percutaneous Interstitial High-Dose-Rate Single-Fraction Brachytherapy for Colorectal Liver Metastases. Int J Radiat Oncol Biol Phys (2010) 77(4):1178-85. doi: 10.1016/j.ijrobp.2009.06.047 
32. Ricke J, Thormann M, Ludewig M, Jungnickel K, Grosser O, Wybranski C, et al. MR-Guided Liver Tumor Ablation Employing Open High-Field 1.0T MRI for Image-Guided Brachytherapy. Eur Radiol (2010) 20(8):1985-93. doi: 10.1007/s00330-010-1751-5

33. Wybranski C, Zeile M, Löwenthal D, Fischbach F, Pech M, Röhl FW, et al. Value of Diffusion Weighted MR Imaging as an Early Surrogate Parameter for Evaluation of Tumor Response to High-Dose-Rate Brachytherapy of Colorectal Liver Metastases. Radiat Oncol (2011) 6(1):43. doi: 10.1186/1748717X-6-43

34. Lüdemann L, Wybranski C, Seidensticker M, Mohnike K, Kropf S, Wust P, et al. In Vivo Assessment of Catheter Positioning Accuracy and Prolonged Irradiation Time on Liver Tolerance Dose After Single-Fraction 192Ir High-Dose-Rate Brachytherapy. Radiat Oncol (2011) 6:107. doi: 10.1186/1748-717X-6-107

35. Kettenbach J, Pokrajac B, Schamp S, Fellner C, Schmid R, Gustorff B, et al. MR-Gestützte Brachytherapie Nichtresektabler Lebermetastasen. Vorläufige Technische Und Klinische Erfahrungen [MRI-Assisted Brachytherapy of Nonresectable Liver Metastases. Preliminary Technical and Clinical Experiences]. Radiologe (2001) 41(1):56-63. doi: 10.1007/s001170050927

36. Mazzola R, Fersino S, Alongi P, Di Paola G, Gregucci F, Aiello D, et al. Stereotactic Body Radiation Therapy for Liver Oligometastases: Predictive Factors of Local Response by 18 F-FDG-PET/Ct. Br J Radiol (2018) 91 (1088):20180058. doi: 10.1259/bjr.20180058

37. Karagiannis E, Leczynski A, Tselis N, Psanis E, Steckenreiter O, Milickovic N, et al. Inverse Planning and Inverse Implanting for Breast Interstitial Brachytherapy. Introducing a New Anatomy Specific Breast Interstitial Template (ASBIT). Radiother Oncol (2018) 128(3):421-7. doi: 10.1016/ j.radonc.2018.06.003

38. Gorissen BL, den Hertog D, Hoffmann AL. Mixed Integer Programming Improves Comprehensibility and Plan Quality in Inverse Optimization of Prostate HDR Brachytherapy. Phys Med Biol (2013) 58:1041-57. doi: 10.1088/ 0031-9155/58/4/1041

39. Karabis A, Giannouli S, Baltas D. HIPO: A Hybrid Inverse Treatment Planning Optimization Algorithm in HDR Brachytherapy. Radiother Oncol (2005) 76:S29. doi: 10.1016/S0167-8140(05)81018-7

40. Lahanas M, Baltas D, Zamboglou N. A Hybrid Evolutionary Algorithm for Multi- Objective Anatomy-Based Dose Optimization in High-Dose-Rate Brachytherapy. Phys Med Biol (2003) 48:399-415. doi: 10.1088/0031-9155/ 48/3/309

41. Ricke J, Wust P, Wieners G, Beck A, Cho CH, Seidensticker M, et al. Liver Malignancies: CT-Guided Interstitial Brachytherapy in Patients With Unfavorable Lesions for Thermal Ablation. J Vasc Interv Radiol (2004) 15(11):1279-86. doi: 10.1097/01.RVI.0000141343.43441.06

42. Wieners G, Schippers AC, Collettini F, Schnapauff D, Hamm B, Wust P, et al. CT-Guided High-Dose-Rate Brachytherapy in the Interdisciplinary Treatment of Patients With Liver Metastases of Pancreatic Cancer. Hepatobiliary Pancreat Dis Int (2015) 14(5):530-8. doi: 10.1016/S1499-3872 (15)60409-X

43. Schippers AC, Collettini F, Steffen IG, Wieners G, Denecke T, Pavel M, et al. Initial Experience With CT-Guided High-Dose-Rate Brachytherapy in the Multimodality Treatment of Neuroendocrine Tumor Liver Metastases. J Vasc Interv Radiol (2017) 28(5):672-82. doi: 10.1016/j.jvir.2016.07.011

44. Wieners G, Mohnike K, Peters N, Bischoff J, Kleine-Tebbe A, Seidensticker R, et al. Treatment of Hepatic Metastases of Breast Cancer With CT-Guided Interstitial Brachytherapy - A Phase II-Study. Radiother Oncol (2011) 100 (2):314-9. doi: 10.1016/j.radonc.2011.03.005

45. Kieszko D, Cisek P, Kordzińska-Cisek I, Grzybowska-Szatkowska L. Treatment of Hepatic Metastases With Computed Tomography-Guided Interstitial Brachytherapy. Oncol Lett (2018) 15(6):8717-22. doi: 10.3892/ ol.2018.8415

46. Collettini F, Schreiber N, Schnapauff D, Denecke T, Wust P, Schott E, et al. CT-Guided High-Dose-Rate Brachytherapy of Unresectable Hepatocellular Carcinoma. Strahlenther Onkol (2015) 191(5):405-12. doi: 10.1007/s00066014-0781-3

47. Collettini F, Golenia M, Schnapauff D, Poellinger A, Denecke T, Wust P, et al. Percutaneous Computed Tomography-Guided High-Dose-Rate Brachytherapy Ablation of Breast Cancer Liver Metastases: Initial Experience With 80 Lesions. J Vasc Interv Radiol (2012) 23(5):618-26. doi: 10.1016/j.jvir.2012.01.079
48. Hass P, Steffen IG, Powerski M, Mohnike K, Seidensticker M, Meyer F, et al. First Report on Extended Distance Between Tumor Lesion and Adjacent Organs at Risk Using Interventionally Applied Balloon Catheters: A Simple Procedure to Optimize Clinical Target Volume Covering Effective Isodose in Interstitial High-Dose-Rate Brachytherapy of Liver Malignomas. J Contemp Brachyther (2019) 11(2):152-61. doi: 10.5114/jcb.2019.84798

49. Beaulieu L, Carlsson Tedgren A, Carrier JF, Davis SD, Mourtada F, Rivard MJ, et al. Report of the Task Group 186 on Model-Based Dose Calculation Methods in Brachytherapy Beyond the TG-43 Formalism: Current Status and Recommendations for Clinical Implementation. Med Phys (2012) 39 (10):6208-36. doi: 10.1118/1.4747264

50. Nath R, Anderson LL, Luxton G, Weaver KA, Williamson JF, Meigooni AS. Dosimetry of Interstitial Brachytherapy Sources: Recommendations of the AAPM Radiation Therapy Committee Task Group No. 43. American Association of Physicists in Medicine. Med Phys (1995) 22:209-34. doi: $10.1118 / 1.597458$

51. Rivard MJ, Butler WM, DeWerd LA, Huq MS, Ibbott GS, Meigooni AS, et al. Supplement to the 2004 Update of the AAPM Task Group No. 43 Report. Med Phys (2007) 34:2187-205. doi: 10.1118/1.2736790

52. Perez-Calatayud J, Ballester F, Das RK, Dewerd LA, Ibbott GS, Meigooni AS, et al. Dose Calculation for Photon- Emitting Brachytherapy Sources With Average Energy Higher Than $50 \mathrm{Kev}$ : Report of the AAPM and ESTRO. Med Phys (2012) 39:2904-29. doi: 10.1118/1.3703892

53. Schnapauff D, Denecke T, Grieser C, Collettini F, Seehofer D, Sinn M, et al Computed Tomography-Guided Interstitial HDR Brachytherapy (CTHDRBT) of the Liver in Patients With Irresectable Intrahepatic Cholangiocarcinoma. Cardiovasc Intervent Radiol (2012) 35(3):581-7. doi: 10.1007/s00270-011-0249-0

54. Collettini F, Schnapauff D, Poellinger A, Denecke T, Schott E, Berg T, et al. Hepatocellular Carcinoma: Computed-Tomography-Guided High-Dose-Rate Brachytherapy (CT-HDRBT) Ablation of Large (5-7 Cm) and Very Large (7 Cm) Tumours. Eur Radiol (2012) 22(5):1101-9. doi: 10.1007/s00330-0112352-7

55. Denecke T, Stelter L, Schnapauff D, Steffen I, Sinn B, Schott E, et al. CTGuided Interstitial Brachytherapy of Hepatocellular Carcinoma Before Liver Transplantation: An Equivalent Alternative to Transarterial Chemoembolization? Eur Radiol (2015) 25(9):2608-16. doi: 10.1007/ s00330-015-3660-0

56. Jonczyk M, Collettini F, Schnapauff D, Geisel D, Böning G, Feldhaus F, et al. CT-Guided High-Dose Rate Brachytherapy (CT-HDRBT) for Limited $(<4$ $\mathrm{Cm}$ ) and Large (>4 Cm) Tumors. Anticancer Res (2018) 38(10):5843-52. doi: 10.21873/anticanres.12926

57. Tselis N, Chatzikonstantinou G, Kolotas C, Milickovic N, Baltas D, Zamboglou N. Computed Tomography-Guided Interstitial High Dose Rate Brachytherapy for Centrally Located Liver Tumours: A Single Institution Study. Eur Radiol (2013) 23(8):2264-70. doi: 10.1007/s00330-013-2816-z

58. Collettini F, Lutter A, Schnapauff D, Hildebrandt B, Puhl G, Denecke T, et al. Unresectable Colorectal Liver Metastases: Percutaneous Ablation Using CTGuided High-Dose-Rate Brachytherapy (CT-HDBRT). Rofo (2014) 186 (6):606-12. doi: 10.1055/s-0033-1355887

59. Collettini F, Poellinger A, Schnapauff D, Denecke T, Wust P, Braicu IE, et al. CT-Guided High-Dose-Rate Brachytherapy of Metachronous Ovarian Cancer Metastasis to the Liver: Initial Experience. Anticancer Res (2011) 31(8):2597602.

60. Geisel D, Denecke T, Collettini F, Grieser C, Wust P, Thuss-Patience P, et al. Treatment of Hepatic Metastases From Gastric or Gastroesophageal Adenocarcinoma With Computed Tomography-Guided High-Dose-Rate Brachytherapy (CT-HDRBT). Anticancer Res (2012) 32(12):5453-8.

61. Geisel D, Collettini F, Denecke T, Grieser C, Flörcken A, Wust P, et al. Treatment for Liver Metastasis From Renal Cell Carcinoma With ComputedTomography-Guided High-Dose-Rate Brachytherapy (CT-HDRBT): A Case Series. World J Urol (2013) 31(6):1525-30. doi: 10.1007/s00345-012-0981-3

62. Omari J, Heinze C, Damm R, Hass P, Janitzky A, Wendler JJ, et al. Radioablation of Hepatic Metastases From Renal Cell Carcinoma With Image-Guided Interstitial Brachytherapy. Anticancer Res (2019) 39(5):25018. doi: 10.21873/anticanres.13370

63. Drewes R, Omari J, Manig M, Seidensticker M, Hass P, Ricke J, et al. Treatment of Hepatic Pancreatic Ductal Adenocarcinoma Metastases With 
High-Dose-Rate Image-Guided Interstitial Brachytherapy: A Single Center Experience. J Contemp Brachyther (2019) 11(4):329-36. doi: 10.5114/ jcb.2019.87269

64. Mohnike K, Wolf S, Damm R, Seidensticker M, Seidensticker R, Fischbach F, et al. Radioablation of Liver Malignancies With Interstitial High-Dose-Rate Brachytherapy : Complications and Risk Factors. Strahlenther Onkol (2016) 192(5):288-96. doi: 10.1007/s00066-016-0957-0

65. Bertot LC, Sato M, Tateishi R, Yoshida H, Koike K. Mortality and Complication Rates of Percutaneous Ablative Techniques for the Treatment of Liver Tumors: A Systematic Review. Eur Radiol (2011) 21(12):2584-96. doi: 10.1007/s00330-011-2222-3

66. Kron P, Linecker M, Jones RP, Toogood GJ, Clavien PA, Lodge JPA. Ablation or Resection for Colorectal Liver Metastases? A Systematic Review of the Literature. Front Oncol (2019) 9:1052. doi: 10.3389/fonc.2019.01052

67. Glassberg MB, Ghosh S, Clymer JW, Wright GWJ, Ferko N, Amaral JF. Microwave Ablation Compared With Hepatic Resection for the Treatment of Hepatocellular Carcinoma and Liver Metastases: A Systematic Review and MetaAnalysis. World J Surg Oncol (2019) 17(1):98. doi: 10.1186/s12957-019-1632-6
Conflict of Interest: The authors declare that the research was conducted in the absence of any commercial or financial relationships that could be construed as a potential conflict of interest.

Publisher's Note: All claims expressed in this article are solely those of the authors and do not necessarily represent those of their affiliated organizations, or those of the publisher, the editors and the reviewers. Any product that may be evaluated in this article, or claim that may be made by its manufacturer, is not guaranteed or endorsed by the publisher.

Copyright (c) 2022 Karagiannis, Strouthos, Leczynski, Zamboglou and Ferentinos. This is an open-access article distributed under the terms of the Creative Commons Attribution License (CC BY). The use, distribution or reproduction in other forums is permitted, provided the original author(s) and the copyright owner(s) are credited and that the original publication in this journal is cited, in accordance with accepted academic practice. No use, distribution or reproduction is permitted which does not comply with these terms. 